\title{
Chimeric peptidomimetics of SOCS 3 able to interact with JAK2 as anti-inflammatory compounds.
}

Sara La Manna ${ }^{1,2}$, Laura Lopez-Sanz ${ }^{2,3}$, Flavia Anna Mercurio ${ }^{4}$, Sara Fortuna ${ }^{5}$, Marilisa Leone ${ }^{4}$, Carmen Gomez-Guerrero ${ }^{2,3}$ and Daniela Marasco ${ }^{1, *}$

${ }^{1}$ Department of Pharmacy, CIRPEB: Centro Interuniversitario di Ricerca sui Peptidi Bioattivi- University of Naples "Federico II", 80134, Naples, Italy

${ }^{2}$ Renal and Vascular Inflammation Group, Instituto de Investigacion Sanitaria-Fundacion Jimenez Diaz (IIS-FJD), Autonoma University of Madrid (UAM), 28040 Madrid, Spain

${ }^{3}$ Spanish Biomedical Research Centre in Diabetes and Associated Metabolic Disorders (CIBERDEM), 28040 Madrid, Spain

${ }^{4}$ Institute of Biostructures and Bioimaging - CNR, 80134, Naples, Italy

${ }^{5}$ Department of Chemical and Pharmaceutical Sciences, University of Trieste, 34127 Trieste, Italy
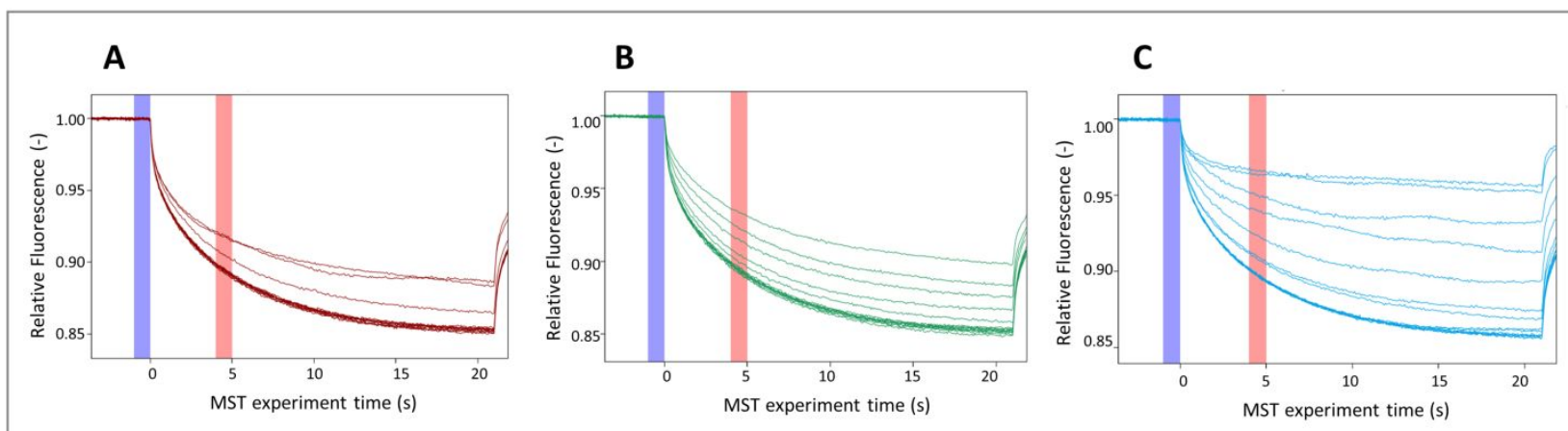

Figure S1. Thermophoretic traces of MST assays for the binding to JAK2 of (A) ESSCONG, (B) restKIRESSCONG, (C) KIRCONG chim peptides. 


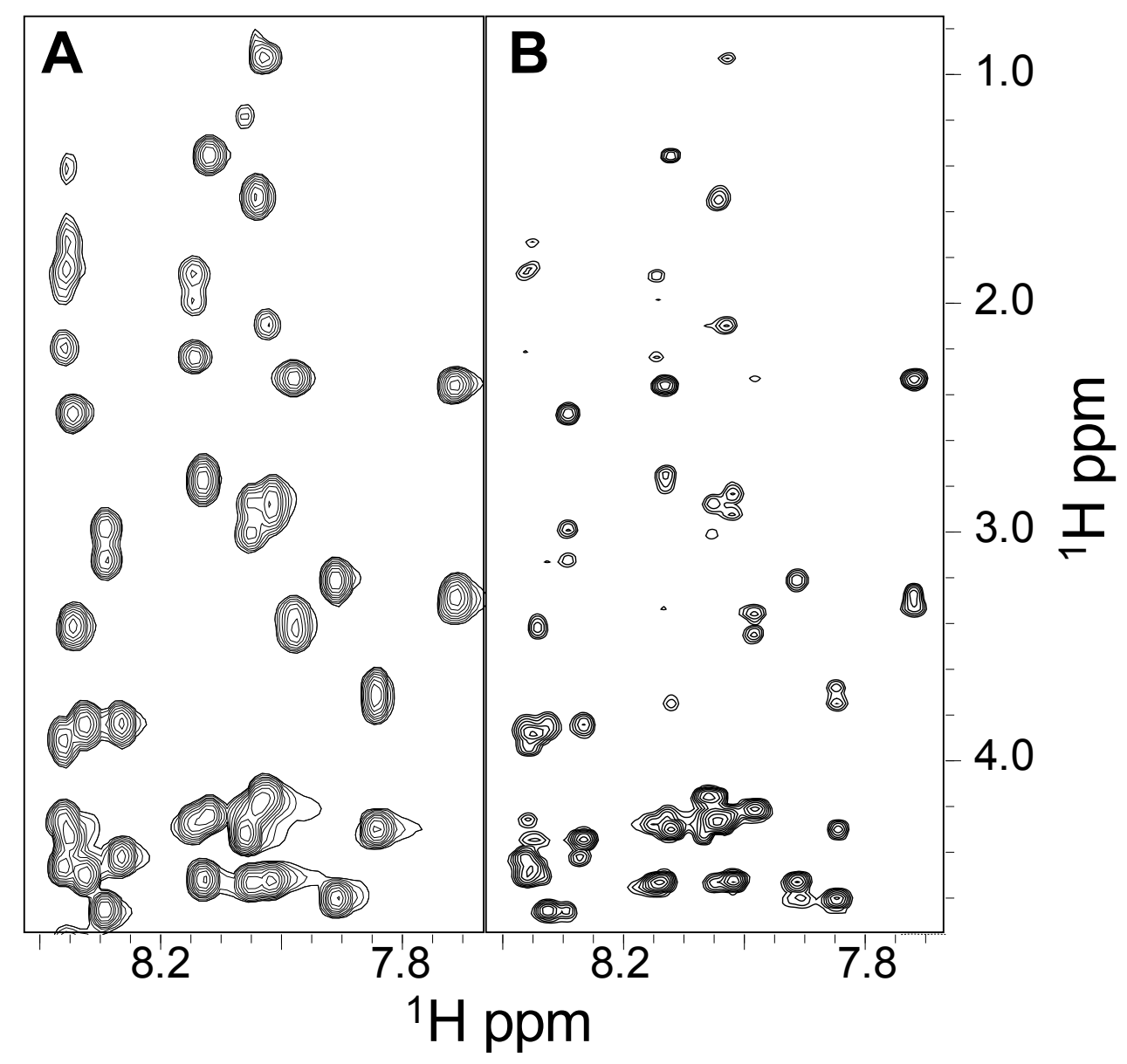

Figure S2. 2D $\left[{ }^{1} \mathrm{H}-{ }^{1} \mathrm{H}\right]$ TOCSY (A) and ROESY 250 (B) spectra of KIRCONG chim peptide in $\mathrm{H}_{2} \mathrm{O}$. Peptide concentration was $770 \mu \mathrm{M}$. The figure shows spectral regions containing $\mathrm{H}_{\mathrm{N}} /$ aliphatic protons correlations. 


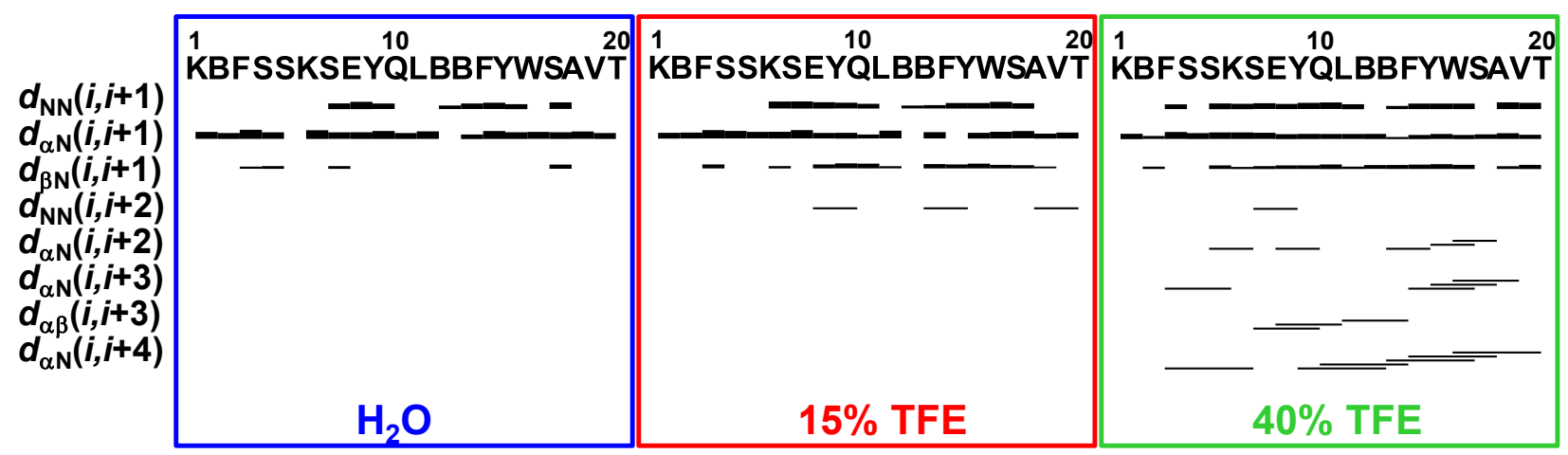

Figure S3. ROE pattern in $\mathrm{H}_{2} \mathrm{O}$ (enclosed in the blue square) obtained from analysis of the ROESY 250 spectrum of the KIRCONG chim peptide; NOE patterns of KIRCONG chim obtained from analyses of NOESY 300 spectra acquired in 15\% TFE and 40\% TFE (highlighted within red and green squares, respectively); "dxy(i,i+z)" denotes a cross-peak between "x" and "y" protons in residues " $i$ " and " $i+z$ ", respectively; the thickness of the lines is proportional to the distance: shorter distances are represented by thicker bars. The amino acid sequence is shown on top with the one letter code; $\mathrm{B}$ indicates the $\beta$-Ala residue. 


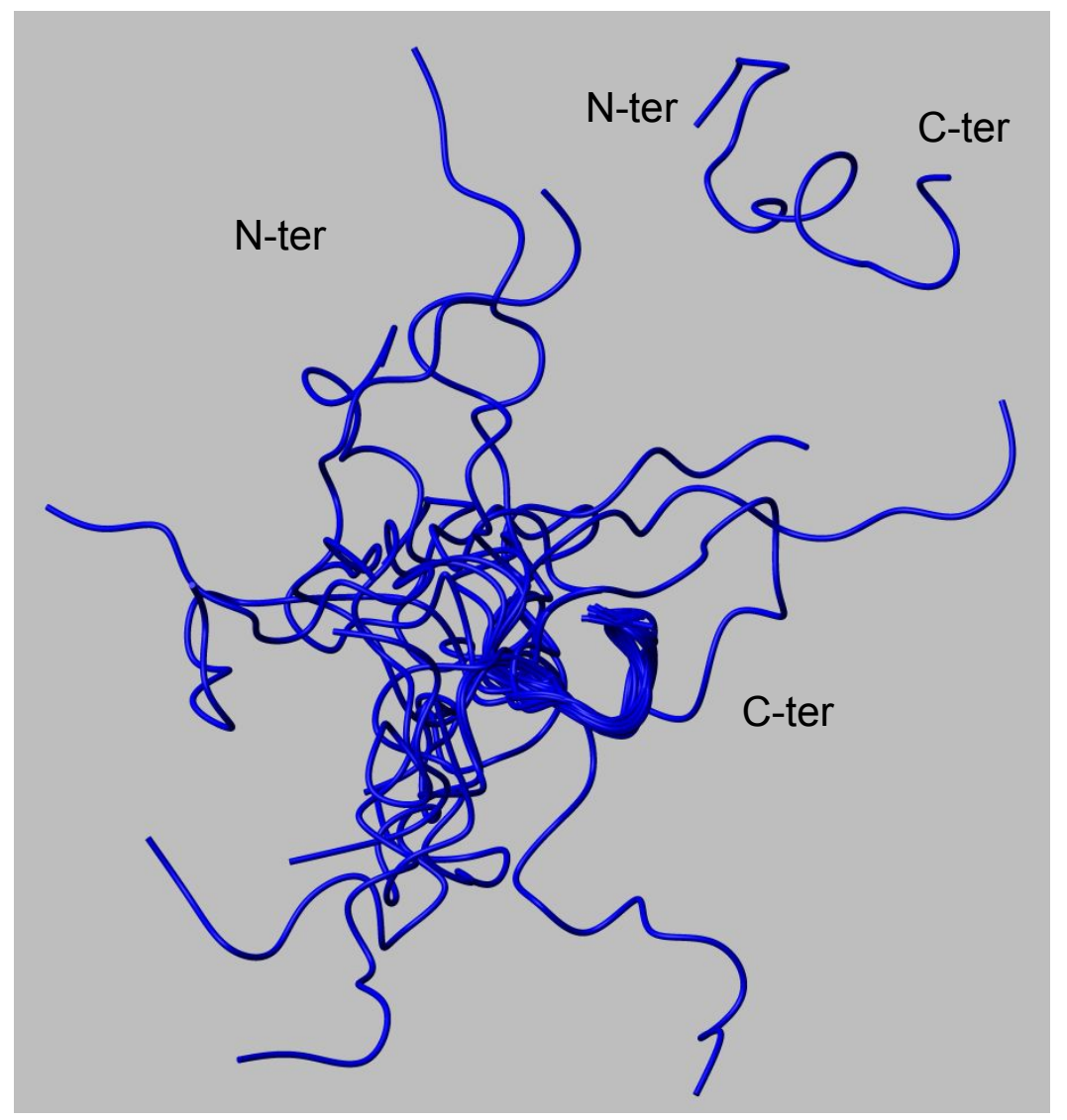

Figure S4. NMR structure of KIRCONG chim peptide calculated in $\mathrm{H}_{2} \mathrm{O}$ : the best 20 conformers are superimposed on the backbone atoms of residues 14-20 (RMSD=1.11 $\AA$ ). The first conformer of the NMR ensemble is also shown in the upper right corner. Structure calculations included 77 upper distance limits (38 intraresidue, 36 short-range, and 3 medium-range) and 91 angular constraints. 


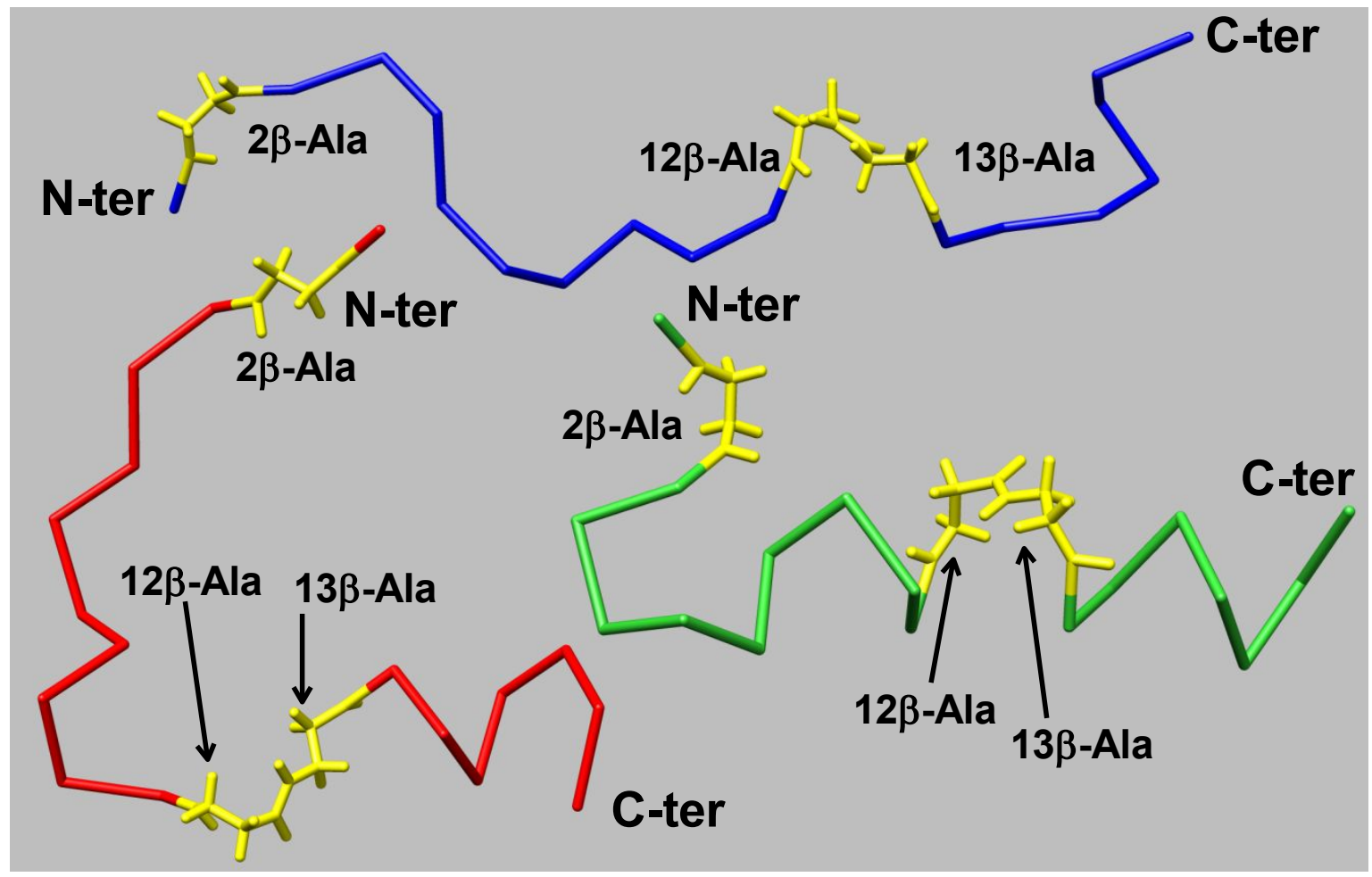

Figure S5. First conformers of KIRCONG chim peptide NMR ensembles in $\mathrm{H}_{2} \mathrm{O}$ (blue), $\mathrm{H}_{2} \mathrm{O} / \mathrm{TFE}$ $(85 / 15, \mathrm{v} / \mathrm{v}, \mathrm{red})$, and $\mathrm{H}_{2} \mathrm{O} / \mathrm{TFE}(60 / 40, \mathrm{v} / \mathrm{v}$, green). The structures are reported in the $\mathrm{C} \alpha$ trace mode with all backbone and side chains atoms of the $\beta$-alanines shown and colored yellow. 


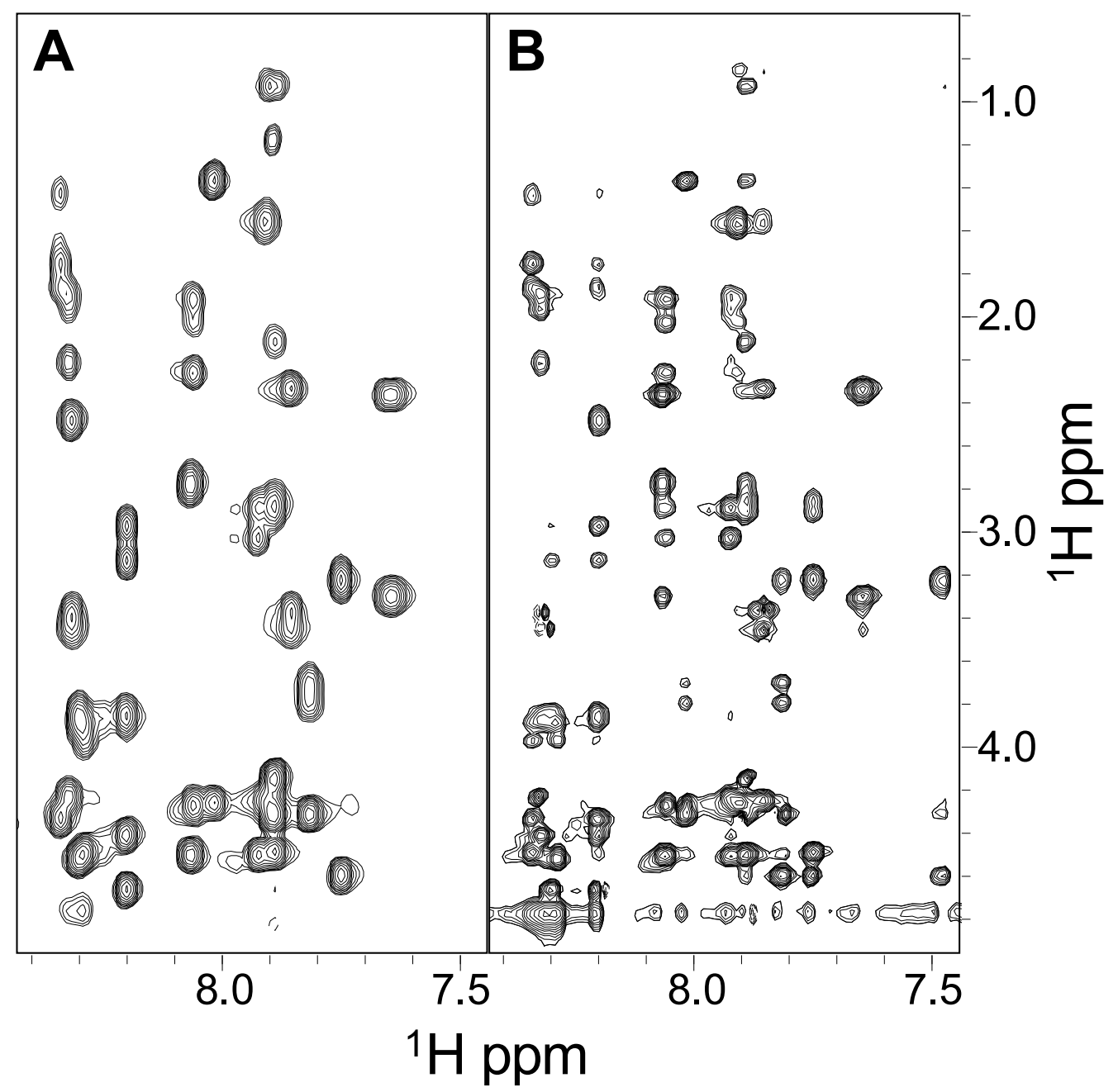

Figure S6. 2D $\left[{ }^{1} \mathrm{H}-{ }^{1} \mathrm{H}\right]$ TOCSY (A) and NOESY 300 (B) spectra of KIRCONG chim peptide in $\mathrm{H}_{2} \mathrm{O} / \mathrm{TFE}(85 / 15, \mathrm{v} / \mathrm{v})$. Peptide concentration was $770 \mu \mathrm{M}$. The regions of the spectra containing $\mathrm{H}_{\mathrm{N}} / \mathrm{H} \alpha$ and side chains correlations are shown. 


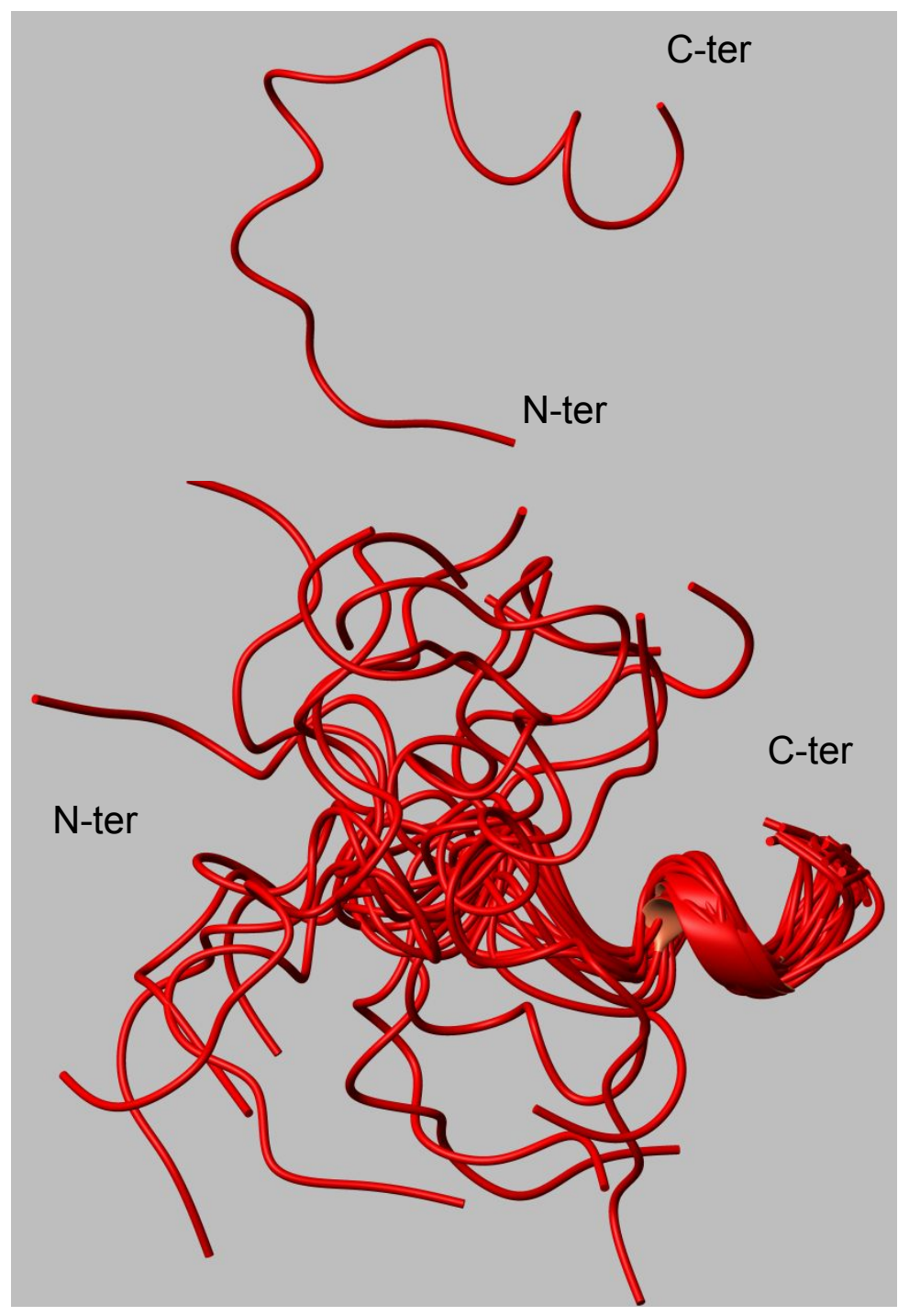

Figure S7. NMR structure of KIRCONG chim peptide in $\mathrm{H}_{2} \mathrm{O} / \mathrm{TFE}(85 / 15, \mathrm{v} / \mathrm{v})$ : the best 20 conformers are superimposed on the backbone N,C,O,CA atoms of residues from 10 to 20 and the $\mathrm{CB}$ atoms of the $\beta$-Ala residues 12 and $13(\mathrm{RMSD}=1.93 \AA$ ). The first conformer of the NMR ensemble is shown in the upper panel. The NMR structure was calculated from 121 upper distance limits (60 intraresidue, 58 short-range, and 3 medium-range) and 79 angle constraints. 


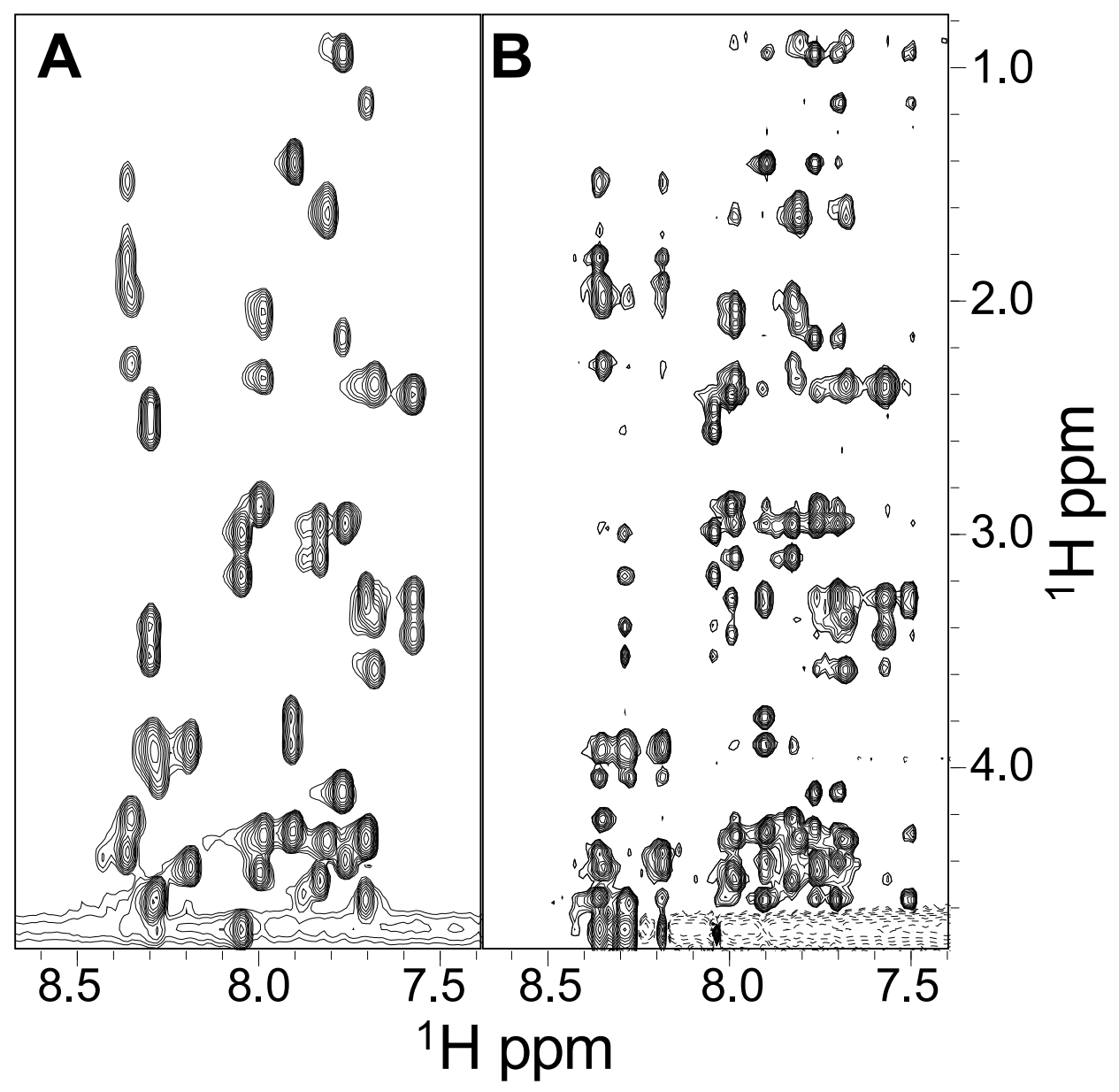

Figure S8. 2D $\left[{ }^{1} \mathrm{H}^{1} \mathrm{H}\right]$ TOCSY (A) and NOESY 300 (B) spectra of KIRCONG chim peptide in $\mathrm{H}_{2} \mathrm{O} / \mathrm{TFE}(60 / 40, \mathrm{v} / \mathrm{v})$. Peptide concentration was $770 \mu \mathrm{M}$. Only the spectral regions containing $\mathrm{H}_{\mathrm{N}} /$ aliphatic protons correlations are shown. 


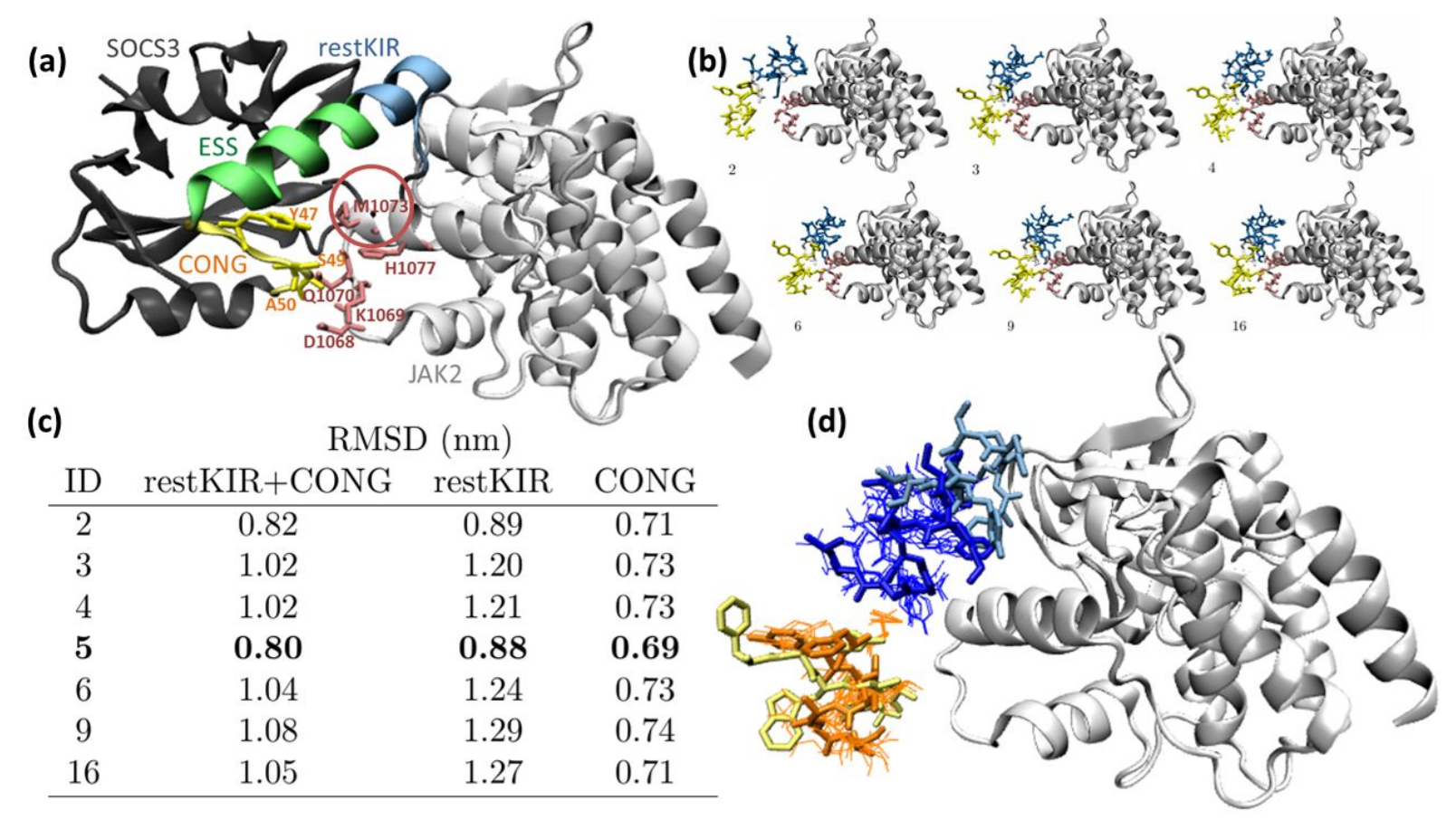

Figure S9. (a) SOCS3/JAK2 (PDB): 4GL9 1, chains A and E) with the fragment restKIRESSCONG and residues described in the text highlighted, and the centre of the docking box subsequently chosen on JAK2 also highlighted (red circle) and (b) selected putative poses of KIRCONG chim docked to JAK2, colour code: JAK2 (white), SOCS3 (gray), restKIR (blue), ESS(green), CONG (yellow). (c) Root mean squared deviation of the restKIR and CONG heavy atom fragments with respect to the same atoms in SOCS3, and (d) their overlap where the optimum pose (ID5 with RMSD $=0.80$ ) represented in orange/dark blue and the SOCS3 fragment yellow/blue are highlighted for comparison. 

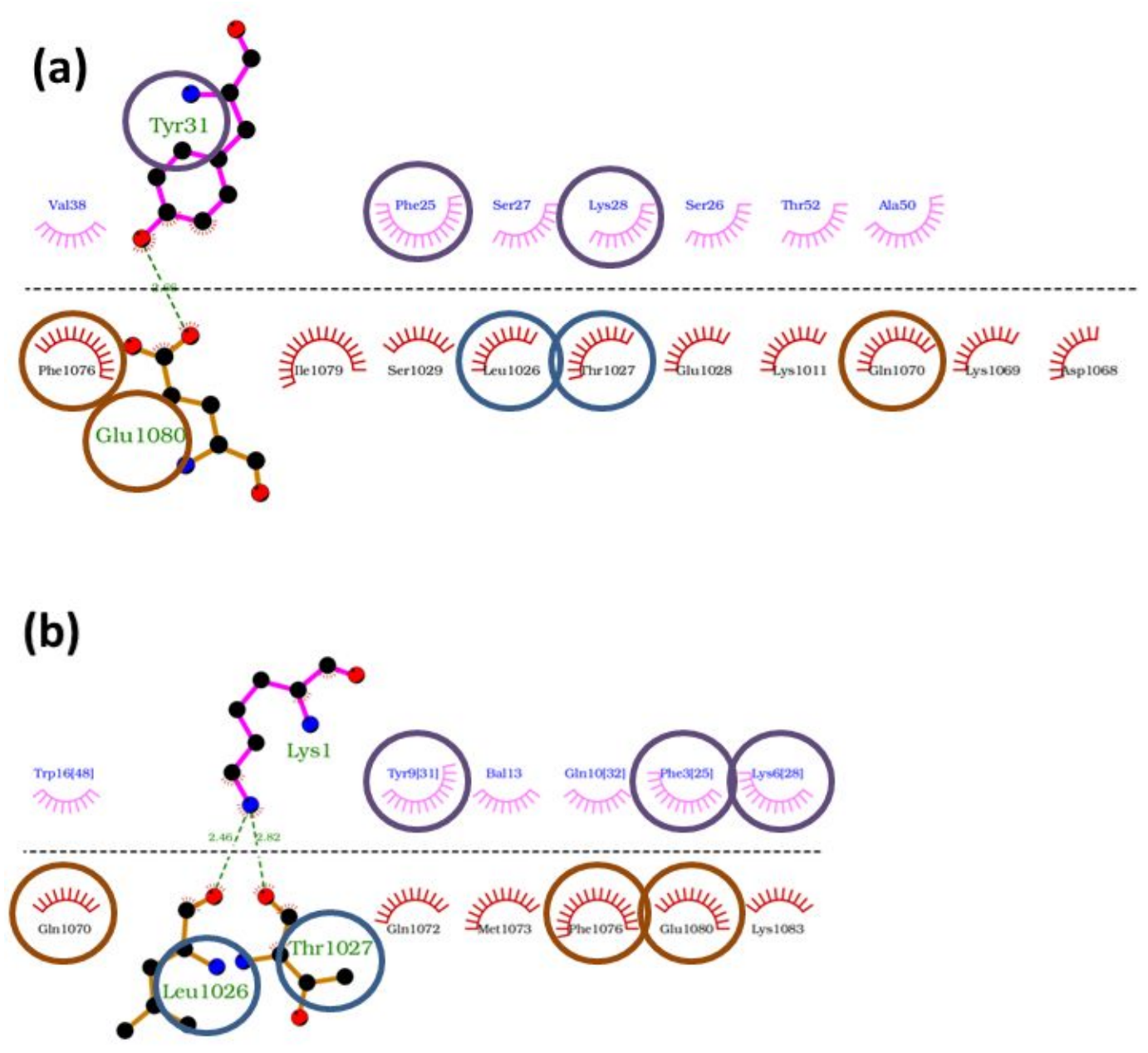

Figure S10. Schematic diagram of (a) the interaction between restKIRESSCONG and JAK2 (configurations extracted from PDB: 4GL9 1, chains A and E), and (b) KIRCONG chim docked to JAK2. Interacting peptides residues are highlighted in pink, while JACK residues are highlighted in red, residues forming hydrogen bonds are green. Hydrogen bonds distances measured in nm are also indicated. On the peptides analogous interacting residues are circled in purple. On JAK2, residues interacting with both peptides are circled (blue if interacting with KIR and brown when interacting with CONG). 
Table S1. ${ }^{1} \mathrm{H}$ chemical shifts of KIRCONG chim peptide in $\mathrm{H}_{2} \mathrm{O}$ at $\mathrm{pH}=4.2$ and $\mathrm{T}=25^{\circ} \mathrm{C}$.

\begin{tabular}{|c|c|c|c|c|c|}
\hline Residue & $\mathbf{H N}$ & $\mathbf{H} \alpha$ & $\mathbf{H} \beta$ & $\mathbf{H} \gamma$ & Others \\
\hline $1 K$ & 8,35 & 3,87 & 1,82 & 1,37 & $\begin{array}{l}\mathrm{H} \delta 1,66 \\
\mathrm{H} \varepsilon 2,95\end{array}$ \\
\hline 2BAL & 8,34 & 2,47 & 3,39 & & \\
\hline $3 F$ & 8,29 & 4,62 & $2,99-3,12$ & & $\begin{array}{l}\mathrm{H} \delta 7,25 \\
\mathrm{H} \varepsilon 7,30 \\
\mathrm{H} \zeta 7,25\end{array}$ \\
\hline $4 S$ & 8,32 & 4,48 & 3,83 & & \\
\hline $5 \mathrm{~S}$ & 8,36 & 4,44 & 3,90 & & \\
\hline $6 K$ & 8,35 & 4,33 & 1,82 & 1,41 & $\begin{array}{l}\mathrm{H} \delta 1,67 \\
\mathrm{H} \varepsilon 2,94 \\
\end{array}$ \\
\hline $7 \mathrm{~S}$ & 8,26 & 4,39 & 3,81 & & \\
\hline $8 E$ & 8,36 & 4,24 & $1,86-1,95$ & 2,18 & \\
\hline $9 Y$ & 8,05 & 4,51 & $2,86-2,99$ & & $\begin{array}{l}\mathrm{H} \delta 7,03 \\
\mathrm{H} \varepsilon 6,77\end{array}$ \\
\hline $10 Q$ & 8,14 & 4,26 & $1,87-1,98$ & 2,22 & Н $\varepsilon 6,82-7,44$ \\
\hline $11 \mathrm{~L}$ & 8,04 & 4,18 & 1,55 & 1,55 & $\begin{array}{c}\delta \mathrm{CH} 3 \\
0,86-0,93 \\
\end{array}$ \\
\hline 12BAL & 7,97 & 2,33 & 3,41 & & \\
\hline 13BAL & 7,72 & 2,35 & 3,28 & & \\
\hline $14 \mathrm{~F}$ & 8,13 & 4,50 & $2,73-2,77$ & & $\begin{array}{l}\mathrm{H} \delta 7,08 \\
\mathrm{H} \varepsilon 7,25\end{array}$ \\
\hline $15 Y$ & 8,02 & 4,51 & $2,85-2,89$ & & $\begin{array}{l}\mathrm{H} \delta 7,00 \\
\mathrm{H} \varepsilon 6,76 \\
\end{array}$ \\
\hline $16 W$ & 7,91 & 4,58 & $3,17-3,21$ & & 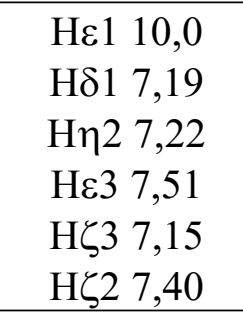 \\
\hline $17 \mathrm{~S}$ & 7,85 & 4,28 & $3,66-3,71$ & & \\
\hline $18 \mathrm{~A}$ & 8,12 & 4,22 & 1,34 & & \\
\hline $19 \mathrm{~V}$ & 8,03 & 4,14 & 2,08 & $0,93-0,94$ & \\
\hline $20 \mathrm{~T}$ & 8,06 & 4,31 & 4,22 & 1,19 & \\
\hline
\end{tabular}


Table S2. Structure statistics of KIRCONG chim peptide NMR structure bundle in $\mathrm{H}_{2} \mathrm{O}$.

\begin{tabular}{|c|c|}
\hline Residual target function, $\AA^{\mathbf{2}}$ & $0.14 \pm 0.05$ \\
\hline Residual NOE violations & 2 \\
\hline Number $\geq 0.1 \AA^{*}$ & 1 \\
\hline Residual angle violations & \\
\hline Atomic pairwise RMSD, $\AA$ & \\
\hline Backbone atoms (all residues) & $4.09 \pm 0.86$ \\
\hline Heavy atoms ( all residues ) & $5.30 \pm 0.79$ \\
\hline Procheck analysis (all residues) ${ }^{\#}$ & \\
\hline Residues in core regions & $18.4 \%$ \\
\hline Residues in allowed regions & $63.9 \%$ \\
\hline Residues in generous regions & $11.6 \%$ \\
\hline Residues in disallowed regions & $6.1 \%$ \\
\hline
\end{tabular}

${ }^{*}$ CYANA ${ }^{2}$ average violations

\#PROCHECK_NMR ${ }^{3}$ statistics 
Table S3. ${ }^{1} \mathrm{H}$ chemical shifts of KIRCONG chim peptide in $\mathrm{H}_{2} \mathrm{O} / \mathrm{TFE}(85 / 15, \mathrm{v} / \mathrm{v})$ at $\mathrm{pH}=4.2$ and $\mathrm{T}=25^{\circ} \mathrm{C}$.

\begin{tabular}{|c|c|c|c|c|c|}
\hline Residue & HN & $\mathbf{H} \boldsymbol{\alpha}$ & $\mathbf{H} \beta$ & $\mathbf{H} \gamma$ & Others \\
\hline $1 K$ & 8,35 & 3,87 & 1,82 & 1,37 & $\begin{array}{l}\mathrm{H} \delta 1,66 \\
\mathrm{H} \varepsilon 2,95 \\
\end{array}$ \\
\hline 2BAL & 8,34 & 2,47 & 3,39 & & \\
\hline $3 F$ & 8,29 & 4,62 & $2,99-3,12$ & & $\begin{array}{l}\mathrm{H} \delta 7,25 \\
\mathrm{H} \varepsilon 7,30 \\
\mathrm{H} \zeta 7,25\end{array}$ \\
\hline $4 S$ & 8,32 & 4,48 & 3,83 & & \\
\hline $5 \mathrm{~S}$ & 8,36 & 4,44 & 3,90 & & \\
\hline $6 K$ & 8,35 & 4,33 & 1,82 & 1,41 & $\begin{array}{l}\text { H } \delta 1,67 \\
\text { Hع 2,94 }\end{array}$ \\
\hline $7 \mathrm{~S}$ & 8,26 & 4,39 & 3,81 & & \\
\hline $8 E$ & 8,36 & 4,24 & $1,86-1,95$ & 2,18 & \\
\hline $9 Y$ & 8,05 & 4,51 & $2,86-2,99$ & & $\begin{array}{l}\mathrm{H} \delta 7,03 \\
\mathrm{H} \varepsilon 6,77\end{array}$ \\
\hline 10Q & 8,14 & 4,26 & $1,87-1,98$ & 2,22 & Нع 6,82-7,44 \\
\hline $11 \mathrm{~L}$ & 8,04 & 4,18 & 1,55 & 1,55 & $\begin{array}{c}\delta \mathrm{CH} 3 \\
0,86-0,93\end{array}$ \\
\hline 12BAL & 7,97 & 2,33 & 3,41 & & \\
\hline 13BAL & 7,72 & 2,35 & 3,28 & & \\
\hline $14 \mathrm{~F}$ & 8,13 & 4,50 & $2,73-2,77$ & & $\begin{array}{l}\mathrm{H} \delta 7,08 \\
\mathrm{H} \varepsilon 7,25\end{array}$ \\
\hline $15 Y$ & 8,02 & 4,51 & $2,85-2,89$ & & $\begin{array}{l}\mathrm{H} \delta \text { 7,00 } \\
\mathrm{H} \varepsilon 6,76\end{array}$ \\
\hline $16 W$ & 7,91 & 4,58 & $3,17-3,21$ & & 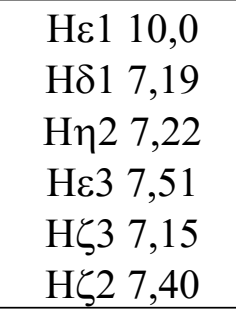 \\
\hline 17S & 7,85 & 4,28 & $3,66-3,71$ & & \\
\hline $18 \mathrm{~A}$ & 8,12 & 4,22 & 1,34 & & \\
\hline $19 \mathrm{~V}$ & 8,03 & 4,14 & 2,08 & $0,93-0,94$ & \\
\hline $20 T$ & 8,06 & 4,31 & 4,22 & 1,19 & \\
\hline
\end{tabular}


Table S4. Structure statistics of KIRCONG chim peptide NMR ensemble in $\mathrm{H}_{2} \mathrm{O} / \mathrm{TFE}(85 / 15$, v/v).

\begin{tabular}{|c|c|}
\hline Residual target function, $\AA^{\mathbf{2}}$ & $0.20 \pm 0.01$ \\
\hline Residual NOE violations & 2 \\
\hline Number $\geq 0.1 \AA^{*}$ & 0 \\
\hline Residual angle violations & \\
\hline Atomic pairwise RMSD, $\AA$ & $3.91 \pm 0.72$ \\
\hline Backbone atoms (all residues) & $5.19 \pm 0.72$ \\
\hline Heavy atoms ( all residues ) & \\
\hline Procheck analysis (all residues) & \\
\hline Residues in core regions & $47.4 \%$ \\
\hline Residues in allowed regions & $40.8 \%$ \\
\hline Residues in generous regions & $7.6 \%$ \\
\hline Residues in disallowed regions & $4.2 \%$ \\
\hline
\end{tabular}

${ }^{*}$ CYANA ${ }^{2}$ average violations ${ }^{\text {\#PROCHECK_NMR }}{ }^{3}$ statistics 
Table S5. ${ }^{1} \mathrm{H}$ chemical shifts of KIRCONG chim peptide in $\mathrm{H}_{2} \mathrm{O} / \mathrm{TFE}(60 / 40, \mathrm{v} / \mathrm{v})$ at $\mathrm{pH}=4.33$ and $\mathrm{T}=25^{\circ} \mathrm{C}$.

\begin{tabular}{|c|c|c|c|c|c|}
\hline Residue & HN & $\mathbf{H} \alpha$ & $\mathbf{H} \beta$ & $\mathbf{H} \gamma$ & Others \\
\hline $1 K$ & & 3,91 & 1,89 & 1,44 & $\begin{array}{l}\mathrm{H} \delta 1,73 \\
\mathrm{H} \varepsilon \\
\end{array}$ \\
\hline 2BAL & 8,30 & $2,48-2,56$ & $3,40-3,51$ & & \\
\hline $3 F$ & 8,05 & 4,68 & $2,98-3,18$ & & $\begin{array}{l}\mathrm{H} \delta 7,26 \\
\mathrm{H} \varepsilon 7,34\end{array}$ \\
\hline $4 S$ & 8,29 & 4,57 & $3,88-3,92$ & & \\
\hline $5 S$ & 8,27 & 4,54 & $3,94-4,03$ & & \\
\hline $6 K$ & 8,36 & 4,36 & 1,92 & 1,49 & $\begin{array}{l}\text { H } \delta 1,82 \\
\text { Hع } 3,03\end{array}$ \\
\hline $7 S$ & 8,19 & 4,41 & $3,88-3,91$ & & \\
\hline $8 E$ & 8,35 & 4,21 & $1,95-2,00$ & 2,27 & \\
\hline $9 Y$ & 7,83 & 4,47 & $2,96-3,10$ & & $\begin{array}{l}\mathrm{H} \delta 7,10 \\
\mathrm{H} \varepsilon 6,83\end{array}$ \\
\hline $10 Q$ & 7,99 & 4,28 & $2,02-2,08$ & & $\begin{array}{c}\mathrm{H} \varepsilon \\
6,69-7,35\end{array}$ \\
\hline $11 \mathrm{~L}$ & 7,82 & 4,29 & 1,66 & 1,61 & $\begin{array}{c}\delta \mathrm{CH} 3 \\
0,91-0,95\end{array}$ \\
\hline 12BAL & 7,68 & $2,35-2,37$ & $3,35-3,59$ & & \\
\hline 13BAL & 7,58 & $2,37-2,40$ & $3,27-3,43$ & & \\
\hline $14 \mathrm{~F}$ & 7,99 & 4,43 & 2,89 & & $\begin{array}{l}\mathrm{H} \delta 7,29 \\
\mathrm{H} \varepsilon 7,14\end{array}$ \\
\hline $15 Y$ & 7,76 & 4,39 & $2,96-2,98$ & & $\begin{array}{l}\mathrm{H} \delta 6,92 \\
\mathrm{H} \varepsilon 6,74\end{array}$ \\
\hline $16 \mathrm{~W}$ & 7,71 & 4,56 & $3,29-3,31$ & & 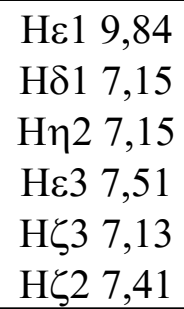 \\
\hline $17 S$ & 7,91 & 4,26 & $3,78-3,91$ & & \\
\hline $18 \mathrm{~A}$ & 7,90 & 4,25 & 1,42 & & \\
\hline $19 \mathrm{~V}$ & 7,77 & 4,10 & 2,15 & $0,94-0,97$ & \\
\hline $20 T$ & 7,70 & 4,29 & 4,26 & 1,16 & \\
\hline
\end{tabular}


Table S6. Structure statistics of KIRCONG chim peptide NMR ensemble in $\mathrm{H}_{2} \mathrm{O} / \mathrm{TFE}(60 / 40$, v/v).

\begin{tabular}{|c|c|}
\hline Residual target function, $\AA^{\mathbf{2}}$ & $0.06 \pm 0.04$ \\
\hline Residual NOE violations & 1 \\
\hline Number $\geq 0.1 \AA^{*}$ & 0 \\
\hline Residual angle violations & \\
\hline Atomic pairwise RMSD, $\AA$ & \\
\hline Backbone atoms (all residues) & $0.72 \pm 0.22$ \\
\hline Heavy atoms ( all residues ) & $1.25 \pm 0.28$ \\
\hline Procheck analysis (all residues) & \\
\hline Residues in core regions & $62.9 \%$ \\
\hline Residues in allowed regions & $28.7 \%$ \\
\hline Residues in generous regions & $7.4 \%$ \\
\hline Residues in disallowed regions & $1.1 \%$ \\
\hline
\end{tabular}

${ }^{*}$ CYANA ${ }^{2}$ average violations \#PROCHECK_NMR ${ }^{3}$ statistics 
Table S7. List of H-bonds calculated with UCSF-Chimera ${ }^{4}$ for all 20 representative KIRCONG chim NMR conformers calculated in $\mathrm{H}_{2} \mathrm{O}$ /TFE (60/40, v/v). UCSF-Chimera default parameters (i.e., constraints relaxed by 0.4 angstroms and 20 degrees) were used for assessing the presence of a H-bond ${ }^{4}$.

\begin{tabular}{|c|c|c|}
\hline Conformer & Acceptor & Donor \\
\hline \multirow{7}{*}{ Model 1} & GLU 8 OE2 & SER 4 N \\
\hline & TYR 9 O & $\beta$-Ala $13 \mathrm{~N}$ \\
\hline & GLN $10 \mathrm{O}$ & PHE $14 \mathrm{~N}$ \\
\hline & $\beta$-Ala $13 \mathrm{O}$ & SER $17 \mathrm{~N}$ \\
\hline & PHE $14 \mathrm{O}$ & ALA $18 \mathrm{~N}$ \\
\hline & TRP $16 \mathrm{O}$ & VAL $19 \mathrm{~N}$ \\
\hline & TRP $16 \mathrm{O}$ & THR $20 \mathrm{~N}$ \\
\hline \multirow{8}{*}{ Model 2} & GLN $10 \mathrm{O}$ & $\beta$-Ala $12 \mathrm{~N}$ \\
\hline & TYR 9 O & $\beta$-Ala $13 \mathrm{~N}$ \\
\hline & GLN $10 \mathrm{O}$ & PHE $14 \mathrm{~N}$ \\
\hline & $\beta$-Ala $13 \mathrm{O}$ & SER $17 \mathrm{~N}$ \\
\hline & PHE $14 \mathrm{O}$ & ALA $18 \mathrm{~N}$ \\
\hline & TRP $16 \mathrm{O}$ & VAL $19 \mathrm{~N}$ \\
\hline & TRP $16 \mathrm{O}$ & THR $20 \mathrm{~N}$ \\
\hline & TRP $16 \mathrm{O}$ & CON2 $21 \mathrm{~N}$ \\
\hline \multirow{7}{*}{ Model 3} & GLN $10 \mathrm{O}$ & $\beta$-Ala $12 \mathrm{~N}$ \\
\hline & TYR 9 O & $\beta$-Ala $13 \mathrm{~N}$ \\
\hline & GLN $10 \mathrm{O}$ & PHE $14 \mathrm{~N}$ \\
\hline & $\beta$-Ala $13 \mathrm{O}$ & SER $17 \mathrm{~N}$ \\
\hline & PHE $14 \mathrm{O}$ & ALA $18 \mathrm{~N}$ \\
\hline & TRP $16 \mathrm{O}$ & VAL $19 \mathrm{~N}$ \\
\hline & TRP $16 \mathrm{O}$ & THR $20 \mathrm{~N}$ \\
\hline \multirow{8}{*}{ Model 4} & GLN $10 \mathrm{O}$ & $\beta$-Ala $12 \mathrm{~N}$ \\
\hline & TYR 9 O & $\beta-$ Ala $13 \mathrm{~N}$ \\
\hline & GLN 100 & PHE $14 \mathrm{~N}$ \\
\hline & $\beta$-Ala $13 \mathrm{O}$ & SER $17 \mathrm{~N}$ \\
\hline & PHE $14 \mathrm{O}$ & ALA $18 \mathrm{~N}$ \\
\hline & TRP $16 \mathrm{O}$ & VAL $19 \mathrm{~N}$ \\
\hline & TRP $16 \mathrm{O}$ & THR $20 \mathrm{~N}$ \\
\hline & TRP $16 \mathrm{O}$ & CON2 $21 \mathrm{~N}$ \\
\hline \multirow{8}{*}{ Model 5} & LYS 60 & SER 7 OG \\
\hline & LYS 60 & GLN 10 NE2 \\
\hline & GLN $10 \mathrm{O}$ & $\beta$-Ala $12 \mathrm{~N}$ \\
\hline & TYR 9 O & $\beta$-Ala $13 \mathrm{~N}$ \\
\hline & GLN $10 \mathrm{O}$ & PHE $14 \mathrm{~N}$ \\
\hline & $\beta$-Ala $13 \mathrm{O}$ & SER $17 \mathrm{~N}$ \\
\hline & TRP 16 O & VAL $19 \mathrm{~N}$ \\
\hline & TRP 160 & THR $20 \mathrm{~N}$ \\
\hline \multirow{4}{*}{ Model 6} & TYR 90 & $\beta$-Ala $13 \mathrm{~N}$ \\
\hline & GLN $10 \mathrm{O}$ & PHE $14 \mathrm{~N}$ \\
\hline & $\beta$-Ala $13 \mathrm{O}$ & SER $17 \mathrm{~N}$ \\
\hline & TRP $16 \mathrm{O}$ & VAL $19 \mathrm{~N}$ \\
\hline
\end{tabular}




\begin{tabular}{|c|c|c|}
\hline & TRP 160 & THR $20 \mathrm{~N}$ \\
\hline \multirow{8}{*}{ Model 7} & GLU 80 & $\beta$-Ala $12 \mathrm{~N}$ \\
\hline & TYR 90 & $\beta$-Ala $13 \mathrm{~N}$ \\
\hline & GLN $10 \mathrm{O}$ & PHE $14 \mathrm{~N}$ \\
\hline & $\beta$-Ala $13 \mathrm{O}$ & SER $17 \mathrm{~N}$ \\
\hline & TYR $15 \mathrm{O}$ & ALA $18 \mathrm{~N}$ \\
\hline & TRP $16 \mathrm{O}$ & VAL $19 \mathrm{~N}$ \\
\hline & TRP 160 & THR $20 \mathrm{~N}$ \\
\hline & SER $17 \mathrm{O}$ & CON2 $21 \mathrm{~N}$ \\
\hline \multirow{5}{*}{ Model 8} & TYR 90 & $\beta$-Ala $13 \mathrm{~N}$ \\
\hline & GLN $10 \mathrm{O}$ & PHE $14 \mathrm{~N}$ \\
\hline & $\beta$-Ala 13 O & SER $17 \mathrm{~N}$ \\
\hline & TRP 16 O & VAL $19 \mathrm{~N}$ \\
\hline & TRP 160 & THR $20 \mathrm{~N}$ \\
\hline \multirow{7}{*}{ Model 9} & GLU 8 OE1 & SER $4 \mathrm{~N}$ \\
\hline & GLU 8 O & $\beta$-Ala $12 \mathrm{~N}$ \\
\hline & TYR 9 O & $\beta$-Ala $13 \mathrm{~N}$ \\
\hline & GLN 100 & PHE $14 \mathrm{~N}$ \\
\hline & $\beta$-Ala 13 O & SER $17 \mathrm{~N}$ \\
\hline & TRP 16 O & VAL $19 \mathrm{~N}$ \\
\hline & TRP 160 & THR $20 \mathrm{~N}$ \\
\hline \multirow{5}{*}{ Model 10} & TYR 9 O & $\beta$-Ala $13 \mathrm{~N}$ \\
\hline & GLN $10 \mathrm{O}$ & PHE $14 \mathrm{~N}$ \\
\hline & $\beta$-Ala $13 \mathrm{O}$ & SER $17 \mathrm{~N}$ \\
\hline & TRP 16 O & VAL $19 \mathrm{~N}$ \\
\hline & TRP $16 \mathrm{O}$ & THR $20 \mathrm{~N}$ \\
\hline \multirow{6}{*}{ Model 11} & GLN $10 \mathrm{O}$ & $\beta$-Ala $12 \mathrm{~N}$ \\
\hline & TYR 9 O & $\beta$-Ala $13 \mathrm{~N}$ \\
\hline & GLN $10 \mathrm{O}$ & PHE $14 \mathrm{~N}$ \\
\hline & $\beta$-Ala $13 \mathrm{O}$ & SER $17 \mathrm{~N}$ \\
\hline & TRP 16 O & VAL $19 \mathrm{~N}$ \\
\hline & TRP 160 & THR $20 \mathrm{~N}$ \\
\hline \multirow{6}{*}{ Model 12} & GLN $10 \mathrm{O}$ & $\beta$-Ala $12 \mathrm{~N}$ \\
\hline & TYR 9 O & $\beta$-Ala $13 \mathrm{~N}$ \\
\hline & GLN $10 \mathrm{O}$ & PHE $14 \mathrm{~N}$ \\
\hline & $\beta$-Ala 13 O & SER $17 \mathrm{~N}$ \\
\hline & TRP 160 & VAL $19 \mathrm{~N}$ \\
\hline & TRP 160 & THR $20 \mathrm{~N}$ \\
\hline \multirow{6}{*}{ Model 13} & TYR 9 O & $\beta$-Ala $12 \mathrm{~N}$ \\
\hline & TYR 9 O & $\beta$-Ala $13 \mathrm{~N}$ \\
\hline & $\beta$-Ala $13 \mathrm{O}$ & SER $17 \mathrm{~N}$ \\
\hline & PHE 14 O & ALA $18 \mathrm{~N}$ \\
\hline & TYR $15 \mathrm{O}$ & ALA $18 \mathrm{~N}$ \\
\hline & TRP 160 & THR $20 \mathrm{~N}$ \\
\hline \multirow{4}{*}{ Model 14} & LYS 60 & SER 7 OG \\
\hline & TYR 9 O & $\beta$-Ala $13 \mathrm{~N}$ \\
\hline & GLN 100 & PHE 14 N \\
\hline & $\beta$-Ala 13 O & SER $17 \mathrm{~N}$ \\
\hline
\end{tabular}




\begin{tabular}{|c|c|c|}
\hline & TRP 160 & THR $20 \mathrm{~N}$ \\
\hline \multirow{7}{*}{ Model 15} & SER 4 O & SER 5 OG \\
\hline & GLN $10 \mathrm{O}$ & $\beta$-Ala $12 \mathrm{~N}$ \\
\hline & TYR 9 O & $\beta$-Ala $13 \mathrm{~N}$ \\
\hline & GLN $10 \mathrm{O}$ & PHE $14 \mathrm{~N}$ \\
\hline & $\beta$-Ala 13 O & SER $17 \mathrm{~N}$ \\
\hline & TRP 16 O & THR $20 \mathrm{~N}$ \\
\hline & VAL 190 & THR $20 \mathrm{~N}$ \\
\hline \multirow{7}{*}{ Model 16} & GLU 8 O & $\beta$-Ala $12 \mathrm{~N}$ \\
\hline & TYR 90 & $\beta$-Ala $13 \mathrm{~N}$ \\
\hline & GLN $10 \mathrm{O}$ & PHE $14 \mathrm{~N}$ \\
\hline & $\beta$-Ala $13 \mathrm{O}$ & SER $17 \mathrm{~N}$ \\
\hline & PHE 14 O & ALA $18 \mathrm{~N}$ \\
\hline & TRP 160 & THR $20 \mathrm{~N}$ \\
\hline & SER $17 \mathrm{O}$ & CON2 $21 \mathrm{~N}$ \\
\hline \multirow{8}{*}{ Model 17} & GLN 100 & $\beta$-Ala $12 \mathrm{~N}$ \\
\hline & TYR 90 & $\beta$-Ala $13 \mathrm{~N}$ \\
\hline & GLN $10 \mathrm{O}$ & PHE $14 \mathrm{~N}$ \\
\hline & $\beta$-Ala $13 \mathrm{O}$ & SER $17 \mathrm{~N}$ \\
\hline & PHE 14 O & ALA $18 \mathrm{~N}$ \\
\hline & TYR $15 \mathrm{O}$ & ALA $18 \mathrm{~N}$ \\
\hline & TYR $15 \mathrm{O}$ & VAL $19 \mathrm{~N}$ \\
\hline & TRP 160 & THR $20 \mathrm{~N}$ \\
\hline \multirow{6}{*}{ Model 18} & GLN 100 & $\beta$-Ala $12 \mathrm{~N}$ \\
\hline & TYR 9O & $\beta$-Ala $13 \mathrm{~N}$ \\
\hline & GLN 100 & PHE $14 \mathrm{~N}$ \\
\hline & $\beta$-Ala 13 O & SER $17 \mathrm{~N}$ \\
\hline & PHE $14 \mathrm{O}$ & ALA $18 \mathrm{~N}$ \\
\hline & TRP $16 \mathrm{O}$ & THR $20 \mathrm{~N}$ \\
\hline \multirow{7}{*}{ Model 19} & SER 4 O & SER 5 OG \\
\hline & TYR 9 O & $\beta$-Ala $13 \mathrm{~N}$ \\
\hline & GLN $10 \mathrm{O}$ & PHE $14 \mathrm{~N}$ \\
\hline & $\beta$-Ala $13 \mathrm{O}$ & SER $17 \mathrm{~N}$ \\
\hline & PHE 14 O & ALA $18 \mathrm{~N}$ \\
\hline & TRP 16 O & THR $20 \mathrm{~N}$ \\
\hline & TRP 160 & CON2 $21 \mathrm{~N}$ \\
\hline \multirow{8}{*}{ Model 20} & SER 7 O & LEU $11 \mathrm{~N}$ \\
\hline & TYR 9 O & $\beta$-Ala $13 \mathrm{~N}$ \\
\hline & GLN $10 \mathrm{O}$ & PHE $14 \mathrm{~N}$ \\
\hline & $\beta$-Ala $13 \mathrm{O}$ & SER $17 \mathrm{~N}$ \\
\hline & PHE 14 O & ALA $18 \mathrm{~N}$ \\
\hline & TYR $15 \mathrm{O}$ & ALA $18 \mathrm{~N}$ \\
\hline & TYR $15 \mathrm{O}$ & VAL $19 \mathrm{~N}$ \\
\hline & TRP 160 & THR $20 \mathrm{~N}$ \\
\hline
\end{tabular}


Peptide Synthesis: Solid phase peptide synthesis and purification were performed as already reported ${ }^{5}$. Briefly SOCS3 derived peptides reported in Table 1 were synthesized employing the solid phase method on a $50 \mu \mathrm{mol}$ scale following standard Fmoc strategies of SPPS ${ }^{6}$. They were purified through RP-HPLC and identified as already reported 7. To allow cellular assays, the fragment 48-60 of the HIV Tat protein carrying TAMRA as a fluorophore was conjugated to KIRESS, KIRCONG chim and control peptide (NC) (Table 1) in a stepwise manner. Purified peptides were lyophilized and stored at $-20^{\circ} \mathrm{C}$ until use.

Microscale Thermophoresis: MST experiments were carried out with a Monolith NT 115 system (Nano Temper Technologies) equipped with 100\% LED and 40\% IR-laser power. Labeling of Histagged Catalytic Domain of JAK2 (residues 826-1132) (Carna Bioscences) was achieved with the His-Tag labeling Kit RED-tris-NTA, as already reported ${ }^{8}$. SOCS3 derived peptides were used in the following concentrations: ESSCONG $404 \mu \mathrm{M}$, KIRCONG chim $409 \mu \mathrm{M}$, restKIRESSCONG $408 \mu \mathrm{M}$ in labeling buffer (Nano Temper Technologies); the dye concentration was adjusted to 100 $\mathrm{nM}$ while the protein concentration was $200 \mathrm{nM}$. Subsequently, $100 \mu \mathrm{L}$ of protein and $100 \mu \mathrm{L}$ of dye were incubated in the dark for $30 \mathrm{~min}$. To monitor binding of SOCS3 derived peptides, a serial dilution (1:1) ${ }^{9}$ was carried out by preparing 14-16 samples on average. Premium capillaries were employed for analysis, at $25^{\circ} \mathrm{C}$ in $50 \mathrm{mM}$ Tris- $\mathrm{HCl}, 150 \mathrm{mM} \mathrm{NaCl}, 0.05 \%$ Brij35, $1 \mathrm{mM} \mathrm{DTT}, 10 \%$ glycerol, 15\% TFE buffer at $\mathrm{pH}$ 7.5. An equation implemented by the software MO-S002 MO Affinity Analysis, provided by the manufacturer, was used for fitting data at different concentrations.

Circular Dichroism (CD) Spectroscopy: CD spectroscopy experiments were carried out by employing a Jasco J-810 spectropolarimeter (JASCO Corp, Milan, Italy) at room temperature in the spectral range 190-260 nm and spectra are averaged over two scans, to which blanks were subtracted. CD signals were converted to mean residue ellipticity with $\mathrm{deg}^{*} \mathrm{~cm}^{2 *} \mathrm{dmol}^{-1 *} \mathrm{res}^{-1}$ as units. Scan speed value was $20 \mathrm{~nm} / \mathrm{min}$, band width $2.0 \mathrm{~nm}$, resolution $0.2 \mathrm{~nm}$, sensitivity $50 \mathrm{mdeg}$ and response $4 \mathrm{sec}$. Peptides concentration was $50 \mu \mathrm{M}$ in a quartz cuvette with a path-length of 0.1 $\mathrm{cm}^{10,11}$. Spectra were acquired in $10 \mathrm{mM}$ phosphate buffer at $\mathrm{pH} 7.4$ in mixtures with TFE $(2,2,2$ trifluoroethanol) ${ }^{12}$.

NMR studies: NMR spectra of the KIRCONG chim peptide (as N-term amine free variant) were recorded at $25{ }^{\circ} \mathrm{C}$ on a Varian Unity Inova $600 \mathrm{MHz}$ spectrometer provided with a cold probe. NMR samples were prepared by dissolving the peptide $(0.9 \mathrm{mg})$ either in $\mathrm{H}_{2} \mathrm{O}$ with $10 \% \mathrm{v} / \mathrm{v}_{2} \mathrm{O}$ (98\% D, Sigma-Aldrich, Milan, Italy), or in aqueous mixtures containing 15\% and 40\% v/v 2,2,2trifluoroethanol-D3 (99.5\% isotopic purity, Sigma-Aldrich, Milan, Italy); with final sample 
volumes equal to $500 \mu \mathrm{L}$, for a final peptide concentration of $770 \mu \mathrm{M}$. To conduct NMR structural analyses the following 2D $\left[{ }^{1} \mathrm{H},{ }^{1} \mathrm{H}\right]$ experiments were recorded: TOCSY (Total Correlation Spectroscopy) $)^{13}$, NOESY (Nuclear Overhauser Enhancement Spectroscopy) ${ }^{14}$, ROESY (Rotating Frame Overhauser Enhancement Spectroscopy) ${ }^{15}$ and DQFCOSY (Double Quantum-Filtered Correlated Spectroscopy) ${ }^{16}$. Typical acquisition parameters included 16-64 scans, 128-256 FIDs in t1, 1024 or 2048 data points in t2. Mixing times for TOCSY experiments were set to $70 \mathrm{~ms}$ whereas, a mixing time equal to $300 \mathrm{~ms}$ was used to record NOESY spectra; ROESY experiments were acquired with a mixing time equal to $250 \mathrm{~ms}$. Residual water signal was suppressed through excitation sculpting ${ }^{17}$. A standard strategy was followed to gain proton resonance assignments ${ }^{18}$. Trimethylsilyl-3-propionic acid sodium salt-D4 (TSP) (99\% D, Armar Scientific, Switzerland) was used as internal standard for chemical shifts referencing. The Varian software VNMRJ 1.1D (Varian/Agilent Technologies, Milan, Italy) was implemented to process NMR spectra that were next analyzed with the program NEASY ${ }^{19}$ included in CARA (Computer Aided Resonance Assignment).

NMR Structure calculations and analysis: NMR solution structures of KIRCONG chim peptide in $\mathrm{H}_{2} \mathrm{O}$ and $\mathrm{H}_{2} \mathrm{O}$ /TFE mixtures were calculated with the software CYANA (version 2.1)2. The nonnative amino acid $\beta$-Alanine was built and added to the CYANA ${ }^{2}$ standard residue library. Distance constraints (i.e., upper distance limits) were generated from manual integration of peaks in $2 \mathrm{D}\left[{ }^{1} \mathrm{H}\right.$, $\left.{ }^{1} \mathrm{H}\right]$ NOESY spectra (300 ms mixing time) or $2 \mathrm{D}\left[{ }^{1} \mathrm{H},{ }^{1} \mathrm{H}\right]$ ROESY spectrum for the sample in $\mathrm{H}_{2} \mathrm{O}$; the GRIDSEARCH module of CYANA software was implemented to obtain angular constraints ${ }^{2}$. 100 random conformers were initially generated and in the end the 20 structures provided with the lowest CYANA target functions and better obeying to experimental constraints, were selected as representative NMR conformers and additionally analyzed with the software MOLMOL ${ }^{20}$ and UCSF Chimera ${ }^{4}$, that were also used to generate structure images.

Computational Methods for protein preparation: JAK2 (PDB: 4GL9 ${ }^{1}$, chain A) missing atoms and residues were reconstructed with Swiss Model $^{21}$. The JAK2 was then minimized by performing a steepest descent minimization to be stopped either when the maximum force was lower than $1000.0 \mathrm{~kJ} / \mathrm{mol} / \mathrm{nm}$ or when 50000 minimization steps were performed with $0.005 \mathrm{~kJ} / \mathrm{mol}$ energy step size, with Verlet cutoff scheme, short-range electrostatic cut-off and Van der Waals cut-off of 1.0nm. We used GROMOS 54a7 force field ${ }^{22}$ and run the minimization as implemented in the Gromacs package v. $2016.1^{23}$.

Computational Methods for peptide preparation and docking: 20 ligand structures obtained by NMR were docked (rigid docking) to the SOCS3 binding site on JAK2 with AutoDock ${ }^{24}$. Each 
system was prepared with AutoDock tools. The docking cubic box had $30.0 \AA$ side on all directions and centered on CA of Met1073. Grid spacing was $0.375 \AA$. Each docking based on Lamarckian Genetic Algorithm was performed with 200 runs and 2,500,000 maximum numbers of evaluations and standard parameters. For each starting structure the representative pose of most populated docking cluster was chosen for subsequent analysis. RMSD were calculated on heavy atoms $(\mathrm{C}, \mathrm{N}, \mathrm{O}, \mathrm{S})$ of standard amino acids. 2D ligand-protein interaction diagrams were generated with $\operatorname{LigPlot}+{ }^{25}$.

Serum stability: Peptides were analysed in diluted fetal bovine serum (FBS) at 25\% (w/v) as previously described ${ }^{26}$, at a concentration of $80 \mu \mathrm{M}$. At the following time points: $0,0.5,1,2$ and 4 h, $80 \mu \mathrm{L}$ aliquots of the incubated solutions were mixed with $80 \mu \mathrm{L}$ of $15 \%$ trichloroacetic acid (TCA) and in order to precipitate serum proteins, were incubated at $2{ }^{\circ} \mathrm{C}$ for at least $15 \mathrm{~min}$. Upon a centrifugation $(13,000 \mathrm{rpm}$ for $10 \mathrm{~min})$ the supernatant was recovered. Experiments were carried out in triplicate. Reverse phase high performance liquid chromatography (RP-HPLC) was performed on a Shimadzu HPLC equipped with UV detector using a C18-Kinetek column from Phenomenex (Milan, Italy), by employing a gradient from 10 to $80 \%$ of B (acetonitrile $0.1 \%$ TFA) versus $\mathrm{A}$ (water $0.1 \%$ TFA) in $20 \mathrm{~min}$.

Cell cultures: VSMCs from mouse aorta were isolated by enzymatic digestion, cultured in Dulbecco's Modified Eagle Medium (DMEM) supplemented with 10\% FBS, $100 \mathrm{U} / \mathrm{mL}$ penicillin, $100 \mu \mathrm{g} / \mathrm{mL}$ streptomycin, and $2 \mathrm{mM}$ L-glutamine (Sigma-Aldrich) and used between the $4^{\text {nd }}$ and $7^{\text {th }}$ passages. The murine macrophage cell line RAW 264.7 (TIB-71; American Type Culture Collection) was cultured in DMEM with $10 \% \mathrm{FBS}, 100 \mathrm{U} / \mathrm{mL}$ penicillin, $100 \mu \mathrm{g} / \mathrm{mL}$ streptomycin, and $2 \mathrm{mM}$ L-glutamine (Sigma-Aldrich).

Cells were made quiescent by $24 \mathrm{~h}$ incubation in medium with $0 \% \mathrm{FBS}$, and then were pre-treated for 90 min with peptides (KIRESS, KIRCONG chim and negative control (NC) conjugated to Tat derived cell penetrating sequence, $12.5 \mu \mathrm{M}$ ) before stimulation for $1 \mathrm{~h}$ with recombinant cytokines (IFN $\gamma 10^{3} \mathrm{U} / \mathrm{mL}$ plus IL-6 $10^{2} \mathrm{U} / \mathrm{mL}$; PeproTech).

mRNA expression analysis: The total RNA was extracted from cultured cells using TRIzol (Life Technologies) . Target gene expression (Cxcl10,Ccl5and Nox2) was analyzed in duplicate by realtime quantitative PCR (Applied Biosystem) and normalized to housekeeping gene 18S.

Immunofluorescence studies: VSMCs seeded on glass coverslips were treated for 90min with TAMRA-conjugated peptides before stimulation, then fixed(4\% paraformaldehyde), permeabilized (0.5\% Triton X-100) and incubated with P-STAT3 antibody (Cell Signaling), followed by fluorescein isothiocyanate-conjugated secondary antibody (Sigma-Aldrich) and nuclear 
counterstaining with diamidino-2-phenylindole (Dapi). A confocal fluorescent microscope (Leica) was used to capture images.

Statistical analysis: Results are presented as individual values and mean \pm SEMof 3 independent experiments. Statistical analysis was performed using Prism 5 (GraphPad Software Inc) and Pvalue $<0.05$ was considered significant (ANOVA with Bonferroni’s post-hoc test).

\section{References}

1. Kershaw, N. J.; Murphy, J. M.; Liau, N. P.; Varghese, L. N.; Laktyushin, A.; Whitlock, E. L.; Lucet, I. S.; Nicola, N. A.; Babon, J. J., SOCS3 binds specific receptor-JAK complexes to control cytokine signaling by direct kinase inhibition. Nature structural \& molecular biology 2013, 20 (4), 469.

2. Herrmann, T.; Guntert, P.; Wuthrich, K., Protein NMR structure determination with automated NOE assignment using the new software CANDID and the torsion angle dynamics algorithm DYANA. $J$ Mol Biol 2002, 319 (1), 209-27.

3. Laskowski, R. A.; Rullmannn, J. A.; MacArthur, M. W.; Kaptein, R.; Thornton, J. M., AQUA and PROCHECK-NMR: programs for checking the quality of protein structures solved by NMR. J Biomol NMR 1996, 8 (4), 477-86.

4. Pettersen, E. F.; Goddard, T. D.; Huang, C. C.; Couch, G. S.; Greenblatt, D. M.; Meng, E. C.; Ferrin, T. E., UCSF Chimera--a visualization system for exploratory research and analysis. J Comput Chem 2004, 25 (13), 1605-12.

5. Scognamiglio, P. L.; Di Natale, C.; Leone, M.; Cascella, R.; Cecchi, C.; Lirussi, L.; Antoniali, G.; Riccardi, D.; Morelli, G.; Tell, G.; Chiti, F.; Marasco, D., Destabilisation, aggregation, toxicity and cytosolic mislocalisation of nucleophosmin regions associated with acute myeloid leukemia. Oncotarget 2016, 7 (37), 59129-59143.

6. Fields, G. B.; Noble, R. L., Solid phase peptide synthesis utilizing 9-fluorenylmethoxycarbonyl amino acids. Int J Pept Protein Res 1990, 35 (3), 161-214.

7. Di Natale, C.; Scognamiglio, P. L.; Cascella, R.; Cecchi, C.; Russo, A.; Leone, M.; Penco, A.; Relini, A.; Federici, L.; Di Matteo, A.; Chiti, F.; Vitagliano, L.; Marasco, D., Nucleophosmin contains amyloidogenic regions that are able to form toxic aggregates under physiological conditions. FASEB journal : official publication of the Federation of American Societies for Experimental Biology 2015, 29 (9), 3689-701.

8. Mercurio, F. A.; Di Natale, C.; Pirone, L.; Iannitti, R.; Marasco, D.; Pedone, E. M.; Palumbo, R.; Leone, M., The Sam-Sam interaction between Ship2 and the EphA2 receptor: design and analysis of peptide inhibitors. Scientific reports 2017, 7 (1), 17474.

9. Mercurio, F. A.; Marasco, D.; Di Natale, C.; Pirone, L.; Costantini, S.; Pedone, E. M.; Leone, M., Targeting EphA2-Sam and Its Interactome: Design and Evaluation of Helical Peptides Enriched in Charged Residues. Chembiochem : a European journal of chemical biology 2016, 17 (22), 2179-2188.

10. Roviello, G. N.; Vicidomini, C.; Di Gaetano, S.; Capasso, D.; Musumeci, D.; Roviello, V., Solid phase synthesis and RNA-binding activity of an arginine-containing nucleopeptide. RSC advances 2016, 6 (17), 14140-14148.

11. Roviello, G. N.; Moccia, M.; Sapio, R.; Valente, M.; Bucci, E. M.; Castiglione, M.; Pedone, C.; Perretta, G.; Benedetti, E.; Musumeci, D., Synthesis, characterization and hybridization studies of new nucleogamma-peptides based on diaminobutyric acid. Journal of peptide science : an official publication of the European Peptide Society 2006, 12 (12), 829-35.

12. La Manna, S.; Scognamiglio, P. L.; Di Natale, C.; Leone, M.; Mercurio, F. A.; Malfitano, A. M.; Cianfarani, F.; Madonna, S.; Caravella, S.; Albanesi, C.; Novellino, E.; Marasco, D., Characterization of linear mimetic peptides of Interleukin-22 from dissection of protein interfaces. Biochimie 2017, 138, 106-115. 
13. Griesinger, C.; Otting, G.; Wuthrich, K.; Ernst, R. R., Clean TOCSY for proton spin system identification in macromolecules, 110, 7870-7872. Journal of the American Chemical Society 1988, 110, 7870-7872.

14. Kumar, A.; Ernst, R. R.; Wuthrich, K., A two-dimensional nuclear Overhauser enhancement (2D NOE) experiment for the elucidation of complete proton-proton cross-relaxation networks in biological macromolecules. Biochem Biophys Res Commun 1980, 95 (1), 1-6.

15. Bax, A.; Davis, D. G., Practical Aspects of Two-Dimensional Transverse Noe Spectroscopy. J Magn Reson 1985, 63 (1), 207-213.

16. Piantini, U.; Sorensen, O. W.; Ernst, R. R., Multiple quantum filters for elucidating NMR coupling networks. J Am Chem Soc 1982, 104, 6800-6801.

17. Hwang, T. L.; Shaka, A. J., Water suppression that works. Excitation sculpting using arbitrary waveforms and pulsed field gradients. J Magn Reson 1995, 112, 275-279.

18. Wuthrich, K., NMR of Proteins and Nucleic Acids. Wiley: New York, 1986; p 320.

19. Bartels, C., Xia, T., Billeter, M., Güntert, P. \& Wüthrich, K, The program XEASY for computersupported NMR spectral analysis of biological macromolecules. J. Biomol. NMR 1995, (6), 1-10.

20. Koradi, R.; Billeter, M.; Wuthrich, K., MOLMOL: a program for display and analysis of macromolecular structures. J Mol Graph 1996, 14 (1), 51-5, 29-32.

21. Waterhouse, A.; Bertoni, M.; Bienert, S.; Studer, G.; Tauriello, G.; Gumienny, R.; Heer, F. T.; de Beer, T. A. P.; Rempfer, C.; Bordoli, L., SWISS-MODEL: homology modelling of protein structures and complexes. Nucleic acids research 2018, 46 (W1), W296-W303.

22. Schmid, N.; Eichenberger, A. P.; Choutko, A.; Riniker, S.; Winger, M.; Mark, A. E.; van Gunsteren, W. F., Definition and testing of the GROMOS force-field versions 54A7 and 54B7. European biophysics journal 2011, 40 (7), 843.

23. Pronk, S.; Páll, S.; Schulz, R.; Larsson, P.; Bjelkmar, P.; Apostolov, R.; Shirts, M. R.; Smith, J. C.; Kasson, P. M.; van der Spoel, D., GROMACS 4.5: a high-throughput and highly parallel open source molecular simulation toolkit. Bioinformatics 2013, 29 (7), 845-854.

24. Trott, O.; Olson, A. J., AutoDock Vina: improving the speed and accuracy of docking with a new scoring function, efficient optimization, and multithreading. Journal of computational chemistry 2010, 31 (2), 455-461.

25. Laskowski, R. A.; Swindells, M. B., LigPlot+: multiple ligand-protein interaction diagrams for drug discovery. ACS Publications: 2011.

26. Carotenuto, A.; Auriemma, L.; Merlino, F.; Yousif, A. M.; Marasco, D.; Limatola, A.; Campiglia, P.; Gomez-Monterrey, I.; Santicioli, P.; Meini, S.; Maggi, C. A.; Novellino, E.; Grieco, P., Lead optimization of P5U and urantide: discovery of novel potent ligands at the urotensin-II receptor. Journal of medicinal chemistry 2014, 57 (14), 5965-74. 